\title{
Network Multimedia Table Tennis Teaching Design Based on Embedded Microprocessor
}

\author{
Rong Qi $\mathbb{D}^{1}$ and Rongzhi Li $\mathbb{D}^{2}$ \\ ${ }^{1}$ Institute of Physical Education, Shanghai Normal University, 200234 Shanghai, China \\ ${ }^{2}$ China Table Tennis College, Shanghai University of Sports, 200438 Shanghai, China \\ Correspondence should be addressed to Rong Qi; qq390953464@shnu.edu.cn and Rongzhi Li; lirongzhi@sus.edu.cn
}

Received 19 October 2021; Revised 30 November 2021; Accepted 14 December 2021; Published 18 January 2022

Academic Editor: Haibin Lv

Copyright (c) 2022 Rong Qi and Rongzhi Li. This is an open access article distributed under the Creative Commons Attribution License, which permits unrestricted use, distribution, and reproduction in any medium, provided the original work is properly cited.

\begin{abstract}
Multimedia technology and network technology have been rapidly developed. Embedded Micro Processor Unit (MPU) is a processor with a data width of more than 32 bits, which has relatively high performance and high price. Different from the traditional general-purpose computer, due to the limitation of system size and power consumption, the embedded microprocessor only retains related functions. Embedded processors currently mainly include Am186/88, PowerPC, MIPS, ARM, and other mainstream series, among which ARM occupies the main market share. Computer-Aided Instruction (CAI) is a variety of teaching activities carried out under the assistance of computers, discussing the teaching content. The implementation of computer-assisted teaching has followed the pace of China's education system reform. As far as teaching is concerned, it has not only caused changes in the environment and teaching methods, but most importantly, it has brought about the renewal of educational thoughts and concepts, especially a series of changes in the educational system, methods, and content. This article is based on educational theory, educational planning theory, and educational psychology theory, starting from the integration of network multimedia and table tennis course learning, grasping the teaching characteristics of table tennis course, doing detailed demand analysis and system design, and making full use of advanced information technology that has created a table tennis multimedia network teaching platform. This article discusses the design, development, and application research of the network multimedia table tennis teaching system based on the embedded microprocessor through teaching experiments. Based on the network multimedia table tennis, the network multimedia teaching, extension of the system to other physical education teaching provides suggestions and references and explores the future development direction of the network multimedia teaching system through teaching methods. The experiment proves that each test score of the experimental group is tested by a pair of samples, indicating that the application of the platform increases the communication channels and knowledge acquisition; the method facilitates the management of teachers in teaching and improves the degree of informatization of course teaching.
\end{abstract}

\section{Introduction}

Compared with the existing design schemes and products, this system adds radio frequency card reading and video monitoring functions, and the product functions are more complete. In addition, the system has reasonable cost and practical functions, can solve the current problems in multimedia teaching equipment, and has a certain market prospect. Among many teaching subjects, due to the unique point of physical education, it is determined that sports network multimedia teaching must have its own characteristics and requirements. The mode of physical education teaching is different from other subjects. It is based on skill teaching, supplemented by theoretical teaching, which fully implements the principle that practice is derived from theory and is higher than theory. Since entering the $21 \mathrm{st}$ century, the digital integrated circuit product upgrades speed up, especially in the consumer electronics field; this trend is more obvious. As the core of an embedded system, the embedded processor has been developed rapidly both in 
design methods and manufacturing process. At present, dual-core and multicore processors have become a research hotspot, and dual-core and quad-core processors have already put many mature products on the market in the field of consumer electronics, especially smart phones and tablet computers. The so-called multicore, multicore CPU technology integrates multiple independent physical cores on the same silicon chip. In actual work, multiple cores have the purpose of performance multiplication. Advantages of multicore technology in application have two aspects. On the one hand, it brings more powerful computing performance to users, and the more important aspect is that it can meet the requirements of users for multitasking.

Embedded microcontroller (Microcontroller Unit, MCU) is a simple microprocessor. In the early days, it was mostly 8-bit and 16-bit. At present, some companies also classify parts of their 32-bit processor products as embedded microcontrollers. The on-chip peripheral resources of the microcontroller are generally richer, mainly to achieve control functions without a large number of complex calculations, and are widely used in the field of industrial control, so they are called microcontrollers. Generally speaking, embedded microcontrollers use a certain kind of microprocessor core as the core, integrate ROM, flash memory, RAM and other memory units, bus interfaces, ADC, DAC units, timer/counters, watchdog circuits, I/0 interfaces, etc. The analysis of online learning behavior abroad originated earlier, and many results have been achieved in theory and application. Through the analysis of online learning behavior abroad, it is found that the research on the analysis of online learning behavior abroad is mainly applied research, with more innovative topics and deeper research. Ji et al. verified the applicability of computer-assisted teaching in tennis teaching and pointed out that through the individualization of student learning and the professionalization of teacher guidance to implement computer-assisted teaching methods, to carry out the organic and integrated process of teaching activities and student learning activities [1]. Park et al. proposed the use of CAI technology for auxiliary teaching as one of the important ways for many educators to improve teaching methods [2]. Reza et al. analyze the results of the application in detail and propose appropriate and reasonable countermeasures to the existing problem teaching tennis technology courses and provide suggestions and references for the extension of CAI multimedia software to other sports technology teaching [3].

There have been some tentatively reformed teaching of physical education, and this attempt has slowly. Because of the changes in the physical education curriculum standards, new content has been added to the traditional physical education curriculum learning framework. Park combines classroom teaching with extracurricular self-study through the Internet, so that classroom teaching can be extended and reinforced, thereby alleviating the current problems in the classroom teaching model, such as the large number of students [4]. Li suggested combining classroom teaching and extracurricular self-teaching through the Internet to expand and enhance classroom teaching, thereby alleviating the large difference in teaching methods [5]. Kang and
Youm use the multimedia network to effectively carry out auxiliary teaching, carry out the modernization of public sports theory teaching methods, improve the quality of teaching, and promote the development of sports in public sports [6].

To realize a networked teaching platform and help teachers shackle, this paper will design a comprehensive network multimedia table tennis teaching system based on the BS mode, and it will be widely used in online teaching and teaching management of table tennis courses in colleges. The development and use of a multimedia network teaching system for table tennis courses can make up shortcomings mode of table tennis courses, improve teaching efficiency, popularize, and improve table tennis technology; this can more likely course teaching and teaching, and the objective requirement for the vigorous development of table tennis.

\section{Network Multimedia Table Tennis Teaching System Based on Embedded Microprocessor}

\subsection{Network Multimedia Teaching}

2.1.1. Online Teaching. The modern educational necessary means for the reform methods. In a broad sense, online teaching as a new learning environment, fully integrating the dominant position of learners and exploring the organic factors of learning as the main learning method, through the network and multimedia information interaction, students can learn the courses provided by any excellent teacher anywhere $[7,8]$. Online teaching makes the appearance of teaching materials increasingly flexible. It is the most powerful tool to support under the guidance of new teachers. Therefore, it is increasingly favored by university teachers.

2.1.2. The Combination of Multimedia Technology and Network Technology. Integration of multimedia and network, computer-assisted learning environment tends to become a multimedia network, the hot issue that is generally concerned in today's education cycle. The teaching content is organized into teaching information in a human-related way, and a friendly human-computer interaction interface is used to display various media information, so that students can learn through interactive methods $[9,10]$. Communication technologies are closely combined to create a computer network, which not only has multimedia information processing and human-computer interaction functions but also can carry out online multimedia information transmission, shared resource use, and modern communication. The function of the multimedia system is an ideal collaborative learning environment that supports multimedia network teaching.

2.1.3. Features of Multimedia Network Teaching. Teaching characteristic of multimedia network is to combine with the advantages of communication technology. This twoway interactive activity not only enables students to obtain teaching information through visual and auditory methods but also represents an unprecedented interest that students can feel. Online resources are rich and varied, including 
images and text as well as shapes and sounds. The use of the Internet to spread teaching information is conducive to students' participation in a variety of sensory knowledge [11, 12]. From the perspective of students teaching according to their own abilities, the differences of individual students determine the diversity of teaching goals. Online teaching overcomes the shortcomings of traditional teaching that multilevel teaching goals. It can determine the starting point and purpose. From the perspective of the general development of people, online teaching also brings many realities. It contains not only the content taught by teachers in teaching but also the content that teachers cannot express verbally. This also brings rich and colorful life phenomena to the teaching process. It not only promotes students' knowledge and learning but also promotes their development. With the rapid progress of computer and electronic communication technology, embedded technology has also achieved a comprehensive and rapid development. Embedded technology has been widely used in communications and electronic consumer products and has achieved tremendous development in both hardware and software. Particularly in terms of hardware, chips that implement various functions have everything they need, which can meet most of the needs of embedded hardware design and implementation.

\subsubsection{The Mode of Multimedia Network Teaching. Individu-} alized and collaborative teaching can be carried out, and individualized and collaborative teaching can be combined. This teaching method can be completed according to personal needs. Regardless of the teaching content, time, location, and teaching methods, you can choose according to the wishes and needs of students. Distance learning system uses computers, multimedia, and virtual reality technology networks to simulate classroom teaching on the Internet, so that teachers and distance learners can learn through the two-way transmission of audio and video teaching information. Exploratory teaching is completely different from pedagogy, and there is no preprepared course content. On the contrary, the teacher sets exploratory goals, requires students to respond, and provides information sources about the goals for students to report when solving problems, in which two or more students interact and collaborate on the same learning content and knowledge of the teaching content $[13,14]$. When the learner encounters difficulties, the learner will help the learner solve the problem. It is entirely possible in the teaching of computer applications and creating a new interactive.

\subsubsection{The Development Trend of Multimedia Network} Teaching. Online teaching system is a brand-new field of computer network. As an auxiliary teaching method, online teaching, it will definitely have transformation educational concept and education system. The key to teaching results is teaching image and sound, and the transmission of realtime teaching image and sound must be strictly synchronized $[15,16]$. On the one hand, it needs to improve the bandwidth and transmission rate of the network; on the other hand, it needs to use new effective compression technology, using knowledge of artificial intelligence and other aspects, using computers to simulate teachers and students, guide the real students' learning process, and reduce the teaching burden of teachers. Although online learning is a major change in teaching methods, the use of multimedia technology and network technology has many advantages.

2.1.6. The Learning Theoretical Basis of Multimedia Network Teaching. It emphasizes the role of reinforcement and proposes the principles and procedures of reinforcement; the process of shaping behavior reflects the number of times the conditions are met. The various assistance arrangements formed by the combination of the time interval between needs and assistance have therefore formed the idea of linking learning with machines and promoting the development of educational technology $[17,18]$. Context-based teaching is the basic requirement of a student's learning environment. This situation should be familiar to students, which is conducive to solving learning problems. The essence of online teaching is that the teacher is in an online environment, is familiar to the students, and achieves dynamics in a high degree of interaction balanced to seek the purpose of optimizing online teaching.

\subsection{Video Coding and Decoding Algorithm of Network Multimedia Table Tennis Teaching System}

2.2.1. TFRC and MIMD Rate Control Algorithm. Multiple instruction streams and multiple data stream MIMD are a technology for parallelism. MIMD computers have multiple asynchronous and independent working processors. MIMD architecture can be used in many application fields such as computer-aided design. MIMD machines can be shared memory or distributed memory categories.

TFRC is a TCP-friendly rate control strategy based on the rate model that is currently widely studied and has excellent performance. TFRC uses the Padhye model as the formula of the rate control strategy, so the algorithm ensures good smoothness and TCP friendliness. It is very suitable for the transmission of multimedia data $[19,20]$.

$$
T_{S}=\frac{S}{\operatorname{RTT} \sqrt{(2 p / 3)+\operatorname{RTO}(3 \sqrt{3 b p / 8}) p\left(1+32 p^{2}\right)}} .
$$

$T_{S}$ is the sending rate calculated by the formula; timeout period generally set to $4 \mathrm{RTT}$; $S$ is the size of the data packet sent; $b$ indicates how many packets should be confirmed for one ACK and generally takes 1 . The most important thing for the TFRC protocol is the calculation of the issuance rate $T_{S}$. According to Equation (1), the parameters RTT and RTT are decisive for the calculation of $T_{S}$. The calculation formula of RTT is as follows:

$$
R \_ \text {sample }=\left(t \_ \text {now }- \text { ts_echo }\right)-t \_ \text {delay } \text {. }
$$

Among them, $R_{-}$sample is a sample of $R_{-}$sample.

$R \_$sample represents the current time, ts_echo represents, and $t_{\text {_delay }}$ represents the experience of the receiver from receiving the data packet to sending the feedback packet 
time delay. To avoid the instantaneous change of RTT, the calculation of RTT uses the weighted average smoothing calculation method as follows:

$$
\mathrm{RTT}=q * \mathrm{RTT}+(1-q) * R_{-} \text {sample. }
$$

The smoothing factor $q$ in the formula is 0.9. The calculation of the probability of loss events needs to rely on the average packet loss interval. For this reason, it is necessary to calculate the nominal arrival time $T$ loss of each lost packet:

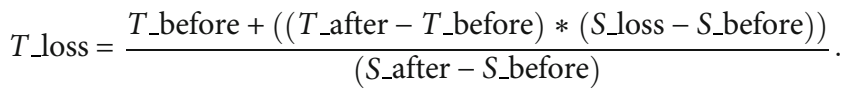

S_loss represents the sequence number of the lost data packet. $S$ loss and $S$ after are the sequence numbers of the latest and correctly arrived data packet before and after the packet loss. From this, the packet loss interval $I_{i}$ can be calculated, and the weighted average calculation of the previous $n$ packet loss intervals of the average packet loss interval $\lambda$ is as follows:

$$
\begin{gathered}
\lambda_{(1, n)}=\frac{\sum_{i=1}^{n} W_{i-1} I_{i}}{\sum_{i=1}^{n} W_{i-1}}, \\
1, \quad i<\frac{n}{2}, \\
W_{i}=\quad \frac{i-((n / 2)-1)}{(n / 2)+1}, \quad \frac{n}{2} \leq i .
\end{gathered}
$$

When calculating the packet loss interval, the time from the last packet loss to the current period is not considered [21]. When this period of time is longer and the data packets during the period increase with the average packet loss interval, this period of time needs to be taken into account and regarded as $I_{0}$. The packet loss interval $\lambda$

$$
\begin{gathered}
\lambda_{(0, n-1)}=\frac{\sum_{i=0}^{n-1} W_{i} I_{i}}{\sum_{i=0}^{n-1} W_{i}}, \\
\lambda=\max \left(\lambda_{(1, n)}, \lambda_{(0, n-1)}\right) .
\end{gathered}
$$

Therefore, the probability of a packet loss event can be expressed as $p=1 / \lambda$.

2.2.2. Shortcomings of the TFRC Algorithm. In the calculation formula of the TFRC algorithm, the parameters that play a decisive role in the result are Rtt and $p$, so the calculation accuracy of these two parameters [22]. For the endto-end delay Rtt, it is composed of transmission delay $\mathrm{Rtt}_{t}$, propagation delay $\mathrm{Rtt}_{\mathrm{pp}}$, processing delay $\mathrm{Rtt}_{\mathrm{ps}}$, and queuing delay $\mathrm{Rtt}_{q}$. The formula for calculating the total delay $\mathrm{Rtt}_{\text {total }}$ is as follows:

$$
\mathrm{Rtt}_{\text {total }}=\mathrm{Rtt}_{t}+\mathrm{Rtt}_{\mathrm{pp}}+\mathrm{Rtt}_{\mathrm{ps}}+\mathrm{Rtt}_{q} .
$$

Among them, $\mathrm{Rtt}_{t}$ and $\mathrm{Rtt}_{\mathrm{ps}}$ can be ignored due to the improvement of equipment performance, which is simplified to

$$
\mathrm{Rtt}_{\mathrm{total}}=\mathrm{Rtt}_{\mathrm{pp}}+\mathrm{Rtt}_{q} \text {. }
$$

The system has an embedded Ethernet interface, and classroom managers can remotely through the campus network. To smoothly realize the remote monitoring and management function, the central control system is also equipped with a camera, and the management personnel can perform reasonable management operations on the classroom multimedia equipment through the remote video image [23]. When multiple streams share the bottleneck bandwidth, the congestion level of each stream is the same, and the queuing delay $\mathrm{Rtt}_{q}$ is basically the same, but due to the difference in the propagation delay $\mathrm{Rtt}_{\mathrm{pp}}$, the total delay will be unfair, as shown in Figure 1.

Online teaching is under the guidance of certain teaching theory and thought, applying multimedia and network technology. It can be seen from the figure that the two links of user 1 and user 2 are obviously different in Rtt, so the rate calculated by the TFRC formula will also be different, but clearly, the two links share the same bottleneck bandwidth and should obtain the same transmission rate. The traditional TFRC formula does not consider this point, so it will lead to varying degrees of decline in fairness and smoothness [24].

2.2.3. Improved Strategy Based on TFRC Algorithm. To improve TFRC multimedia data transmission, these shortcomings have been improved one by one, and the improved TFRC will be used as the rate control strategy of the algorithm in the following. First, propagation delay $\mathrm{Rtt}_{\mathrm{pp}}$ on the fairness of $\mathrm{Rtt}$, we set a variable $\mathrm{Rtt}_{\text {min }}$ at the receiving end to record Rtt when the network is not congested. Since the network is in good condition at this time, the queuing delay $\mathrm{Rtt}_{q}$ can be ignored, so there are

$$
\mathrm{Rtt}_{\min } \cong \mathrm{Rtt}_{\mathrm{pp}}
$$

The calculation method of variable $\mathrm{Rtt}_{\min }$ is as follows:

$$
\begin{aligned}
& \text { if }\left(\mathrm{Rtt}_{\mathrm{cur}}-\mathrm{Rtt}_{\min }<0\right), \\
& \mathrm{Rtt}_{\mathrm{cur}}=\mathrm{Rtt}_{\text {min }}, \quad \mathrm{Rtt},
\end{aligned}
$$

where $\mathrm{Rtt}_{\text {cur }}$ represents the currently measured $\mathrm{Rtt}$, and the final round-trip delay Rtt used when calculating the transmission rate is represented by $\mathrm{Rtt}_{\text {last }}$; then, the calculation formula of $\mathrm{Rtt}_{\text {last }}$ is

$$
\mathrm{Rtt}_{\text {last }}=\mathrm{Rtt}_{\text {total }}-\mathrm{Rtt}_{\text {min }}+\sigma .
$$

The $\sigma$ in the formula represents a constant, which is used to compensate for the propagation delay that affects the fairness of Rtt. The selection of $\sigma$ is very important. A too large $\sigma$ will affect the sensitivity of the algorithm to network 


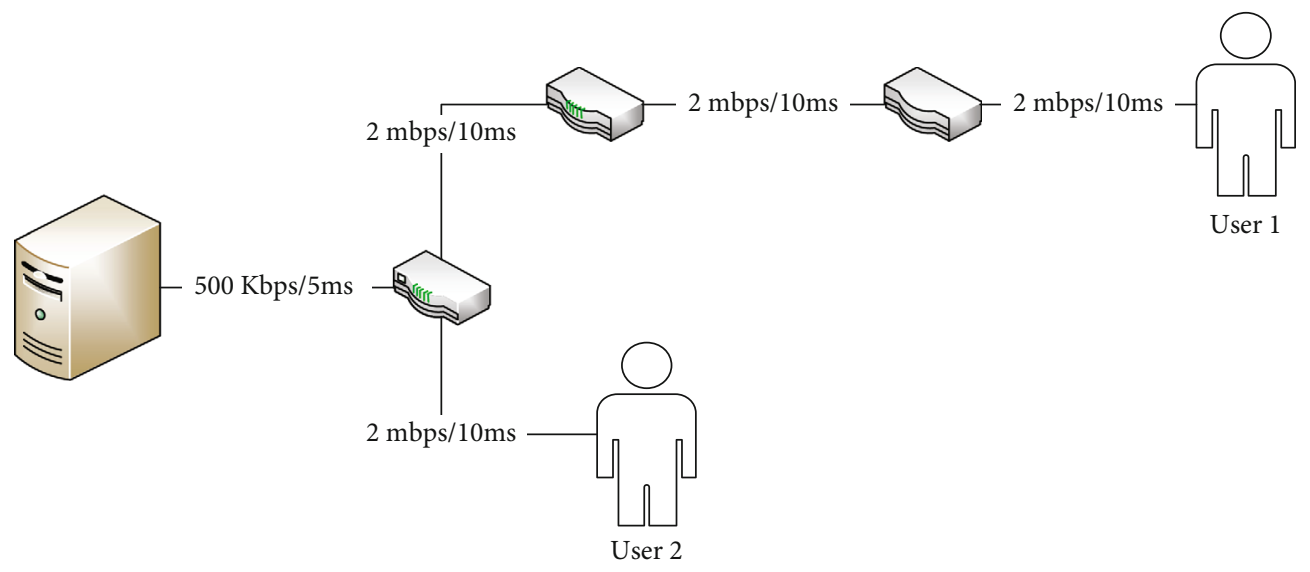

Figure 1: Two broadband links with different numbers of nodes behind the bottleneck bandwidth.

congestion, and a small value will cause the transmission rate shock. The following is the operating mechanism of the improved algorithm:

(1) In the absence of packet loss, the threshold $a$ is introduced. When the relationship between $T_{\text {TFRC }}$ and $T_{\text {NOW }}$ satisfies

$$
1<\frac{T_{\text {TFRC }}}{T_{\text {NOW }}}<a,
$$

$a$ is the corresponding coefficient.

The sending rate $T$

$$
T=T_{\text {TFRC }}
$$

MMU is the abbreviation of Memory Management Unit, the Chinese name (English: abbreviated as PMMU). Kind of computer hardware responsible for processing memory access requests from the central processing unit (CPU). Its functions include virtual address to physical address conversion of the central processing unit cache. In a relatively simple computer architecture, it is responsible for bus arbitration and bank switching (bank switching, especially on 8 -bit systems). When the relationship between $T_{\text {TFRC }}$ and $T_{\text {NOw }}$ does not satisfy Formula (12), the sending rate $T$ is as follows:

$$
T=T_{\text {MIMD }}
$$

(2) In the case of congestion and packet loss, at this time, we threshold $\beta$, when the relationship between $T_{\text {TFRC }}$ and $T_{\text {NOW }}$ satisfies

$$
\beta<\frac{T_{\text {TFRC }}}{T_{\text {NOW }}}<1 .
$$

Using multimedia teaching methods, teaching informa- tion can be loaded, transmitted, and received through a variety of media. Its appearance breaks the traditional chalk and blackboard teaching mode, and while being easy for students to accept, it also greatly reduces the teaching burden of teachers. The realization of all this mainly depends on the use of various teaching equipment in the multimedia classroom. Generally speaking, a multimedia classroom should be equipped with multimedia computers, projectors, electric projection screens, microphones, audio, video booths, and other teaching equipment. The quality of its management will be directly on the classroom knowledge and quality of school. The sending rate $T$ satisfies

$$
T=\frac{\left(T_{\mathrm{TFRC}}+\mathrm{T}_{\mathrm{MIMD}}\right)}{2},
$$

otherwise:

$$
T=T_{\text {MIMD }}
$$

$T$ and $T_{\text {MIMD }}$ have a subordinate relationship.

The improved algorithm solves the effect of excessive Rtt deviation caused by different propagation delays and sudden change of Rtt measurement value on calculation performance.

\section{Experimental Design of Network Multimedia Table Tennis Teaching System}

3.1. Network Multimedia Table Tennis Teaching System. The equipment control module has the output switching function of multiple audio and video sources. It can also realize the shutdown operation of the total power supply of the equipment, the switch operation of the projector, the lifting operation of the electric projection screen, and the common operations of other multimedia equipment through the central controller panel.

The purpose of the network is to serve teaching, promote the modernization, realize the modernization technology, enrich content teaching methods, and build a brand-new education under the needs of the situation. The overall teaching model. Therefore, the research and development of courseware must be sustainable and 


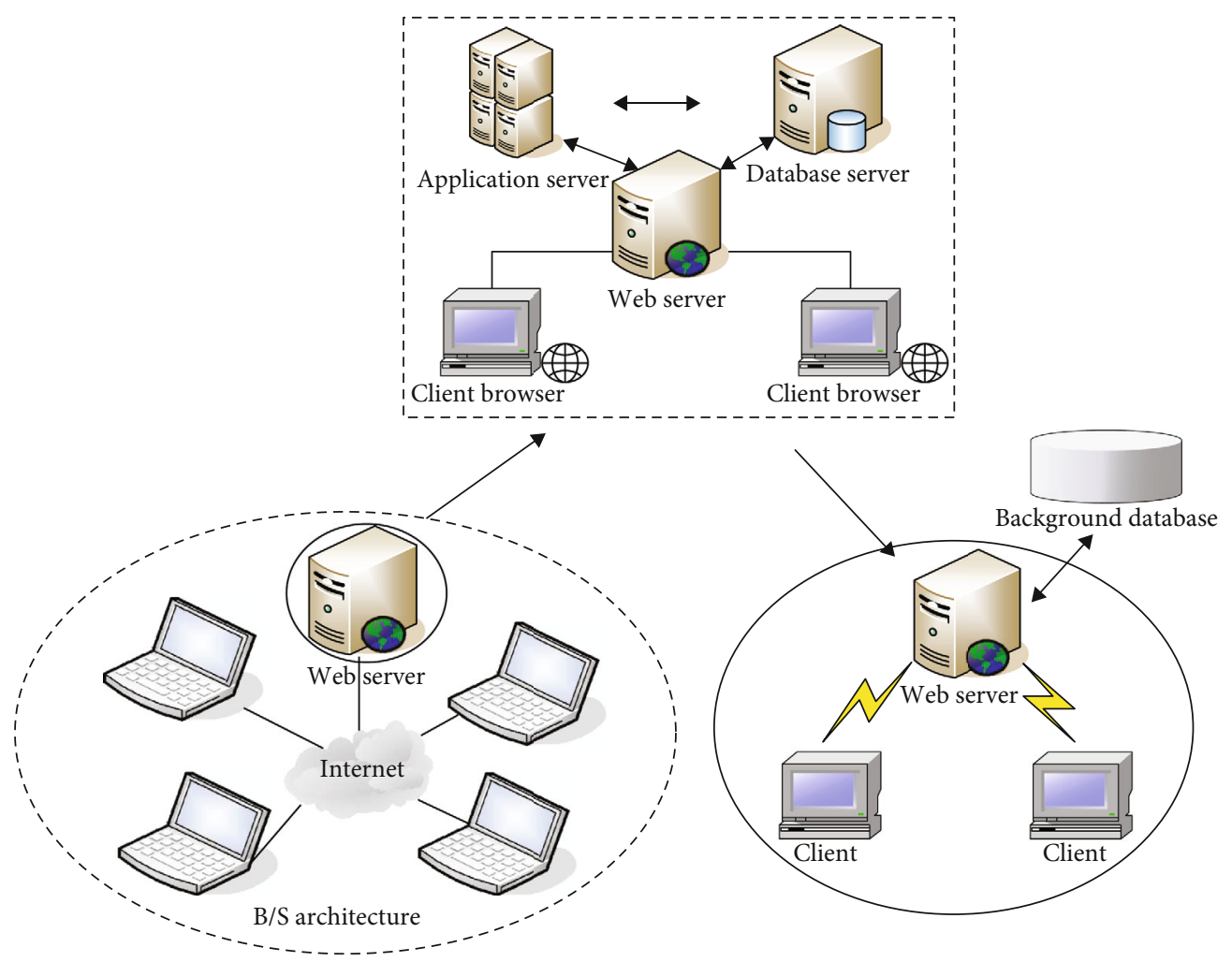

Figure 2: Network multimedia table tennis teaching system architecture.

practical and achieve the expected teaching purpose. The network multimedia table tennis teaching system architecture is shown in Figure 2:

The network multimedia table tennis courseware teaching service system is shown in Figure 3.

The constructed network multimedia teaching service system can ensure the application of multimedia network courseware to teaching practice and can also serve teaching in multiple channels and forms.

3.2. Test Subject. In the research process, the results of the teaching experiment method are integrated, and then, the experiment results of the questionnaire survey method are written. On this basis, a multimedia computer is selected as the central computer of the remote central control room, the existing campus network is used as the transmission channel of control information, and the classroom computer is used as a bridge to connect the centralized controller of each multimedia classroom to the campus network.

Here, we select the students who choose the table tennis elective course in the elective system of University X University as volunteers for this experiment. Among them, there are 46 males and 14 females, a total of 60 students. According to the actual conditions of the students' physical abilities and skills, it is reasonable to divide them into an experimental group (3 groups) and a control group (3 groups), each with 10 people. These 60 people did not experience major sports injuries before and same at the beginning. The basic conditions of the subjects are shown in Table 1. The difference between the basic conditions of the two groups of test players is very small. During the entire experiment, no specific circumstances related to the experiment will be disclosed or hinted to the test players, so that they are completely unaware of the training and try to exclude them. The influence of subjective factors on the experiment. All students were given a one-semester course, in which the experimental group learned through the network multimedia table tennis teaching system and participated in daily table tennis training, while the control group received traditional teaching methods and participated in daily table tennis training. Every 3 weeks, all students will be tested on the basic qualities of table tennis, and the test data will be collected.

\subsection{Experimental Method}

3.3.1. Teaching Experiment Method. Participants were asked to test the basic quality of table tennis. They were divided into groups according to their respective scores. Among them, 3 experimental groups learned through the network multimedia table tennis teaching system and participated in daily table tennis training. The 3 control groups accept traditional teaching methods to learn and participate in daily table tennis training. The monthly test is carried out indoors, such as bad weather in the experiment, and objectivity of the experimental results. Finally, the test data are analyzed and the experimental results are obtained.

3.3.2. Questionnaire Survey. The validity of the questionnaire was tested by the expert evaluation method, and the validity checklist was issued to 10 table tennis teaching and computer network experts. They believed that the content of 


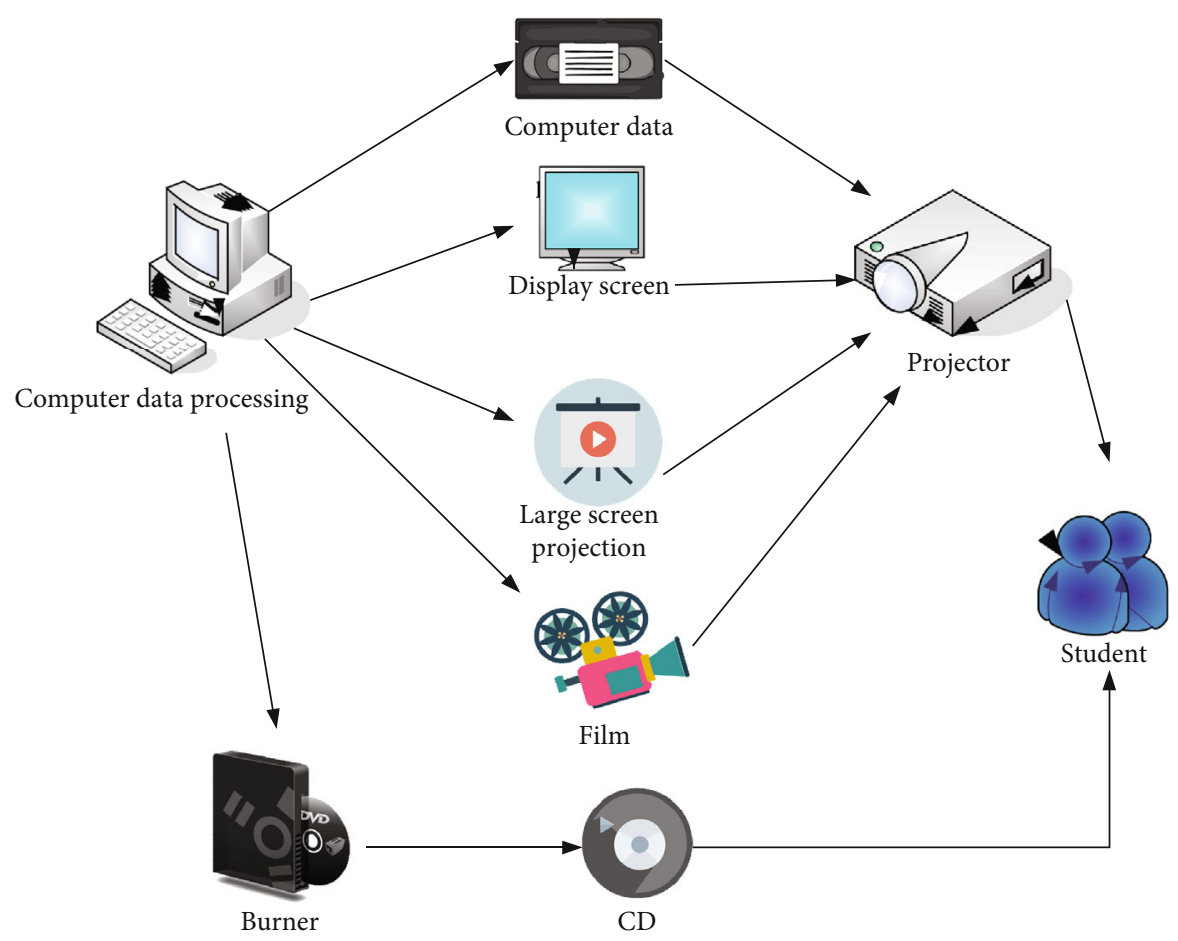

FIGURE 3: Schematic diagram of multimedia network courseware teaching service system.

TABLE 1: Data sheet of basic conditions of experimental subjects.

\begin{tabular}{|c|c|c|c|c|c|}
\hline Group & & Average age & Training years & Average weight & Average height \\
\hline \multirow{3}{*}{ Control group } & $\mathrm{A}$ & $20.7 \pm 0.90$ & 1.60 & $76.4 \pm 4.3$ & $173.5 \pm 5.6$ \\
\hline & B & $20.3 \pm 0.50$ & 1.55 & $72.5 \pm 8.6$ & $176.9 \pm 4.7$ \\
\hline & $\mathrm{C}$ & $20.5 \pm 0.70$ & 1.50 & $74.8 \pm 6.7$ & $169.6 \pm 8.9$ \\
\hline \multirow{3}{*}{ Experiment group } & $\mathrm{D}$ & $20.4 \pm 0.75$ & 1.40 & $75.5 \pm 4.3$ & $172.4 \pm 5.4$ \\
\hline & $\mathrm{E}$ & $20.1 \pm 0.45$ & 1.66 & $78.3 \pm 3.2$ & $178.1 \pm 3.2$ \\
\hline & $\mathrm{F}$ & $20.5 \pm 0.65$ & 1.59 & $70.1 \pm 10.6$ & $170.8 \pm 7.2$ \\
\hline
\end{tabular}

the questionnaire design completely covered the research topic. Students to investigate the students' opinions on the system. The satisfaction of system structure and function, and the satisfaction of students' own interest and recognition attitude of the system, collect these data to analyze and draw conclusions.

3.4. Statistical Data Processing Method. Formula for calculating reliability is shown in Formula (18).

$$
a=\frac{k}{k-1}\left(1-\frac{\sum \sigma_{i}^{2}}{\sigma^{2}}\right) .
$$

\section{Network Multimedia Table Tennis Teaching System}

4.1. Evaluation Index System Based on Index Reliability Testing. From the technical point of view of industrial automation remote control system, the centralized controller for multimedia teaching equipment can also be regarded as a kind of industrial field intelligent controller. It has all main features of industrial field intelligent control equipment, but it is specially designed and designed. The equipment used in multimedia classrooms controls such special "industrial scenes." The reliability of the questionnaire is analyzed, and the reliability of the questionnaire is analyzed through SPSS. The evaluation results are shown in Table 2.

It can be seen from Figure 4 that the data obtained through the questionnaire is calculated by SPSS statistical software to obtain an overall evaluation $\alpha$ coefficient of 0.802 . The content $\alpha$ coefficient of this questionnaire survey was evaluated as 0.729 , and the structure $\alpha$ coefficient was evaluated as 0.736 . It can be seen from the results that the reliability score of this questionnaire can meet the standard reliability of the questionnaire.

\subsection{System Platform Test}

4.2.1. Functional Test. Test function of the system and the results are shown in Table 3 . 
TABLe 2: Data sheet of evaluation index system for index reliability testing.

\begin{tabular}{lccccc}
\hline & Very clear and convenient & Clear and convenient & General & Not clear enough & Chaotic \\
\hline Overall evaluation & 0.439 & 0.363 & 0.116 & 0.068 & 0.014 \\
Evaluation of traditional teaching methods & 0.375 & 0.386 & 0.109 & 0.109 & 0.021 \\
Evaluation of multimedia course learning & 0.463 & 0.309 & 0.134 & 0.065 \\
Content evaluation & 0.386 & 0.343 & 0.137 & 0.098 & 0.29 \\
Structure evaluation & 0.362 & 0.374 & 0.119 & 0.089 \\
\hline
\end{tabular}

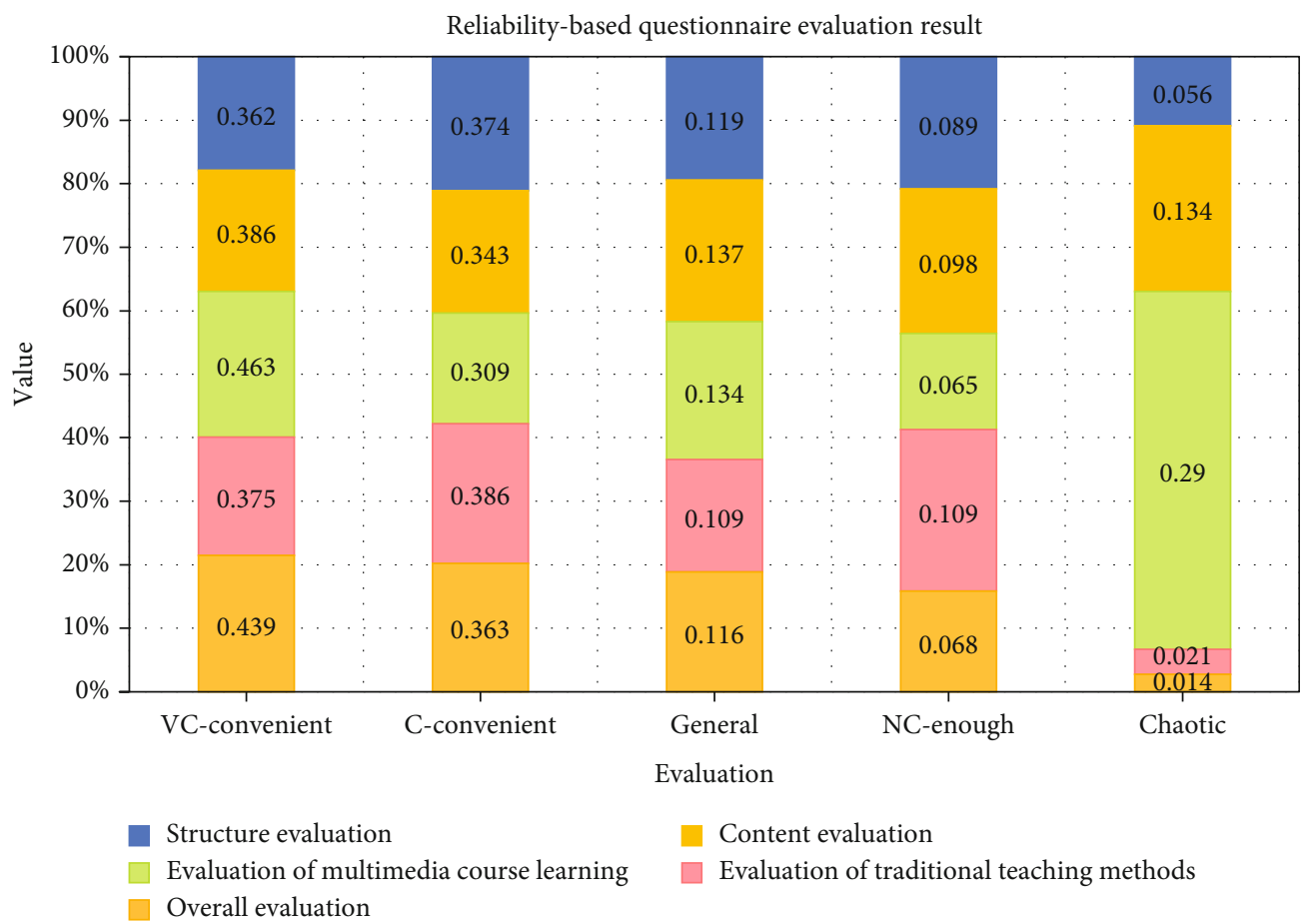

FIgURE 4: Reliability-based questionnaire evaluation result graph.

TABLE 3: System function test table.

\begin{tabular}{lcc}
\hline Functional module & Function name & Test results \\
\hline Login/registration module & Registered & Success \\
& Login & Success \\
& Action explanation & Success \\
& Action & Success \\
& demonstration & \\
Main functions of the system & Technical points & Success \\
& Technical analysis & Success \\
& Practice method & Success \\
& Error correction & Success \\
& Classwork & Success \\
\hline
\end{tabular}

From the test results in Table 3, we can see the effectiveness of the system function. The system function test is relatively successful, and the effect and function of the module are guaranteed.

4.2.2. Running Status Test Analysis. Will it cause system startup failure, scheduling disorder, abnormal end freeze, or concurrent exceptions (0 means no; 1 means yes). Draw conclusions and analyze and put forward corresponding countermeasures and suggestions on this basis, as shown in Figure 5.

From the results in Figure 5, it can be seen that when the number of people logged in at the same time exceeds 200, the system starts to freeze and make errors, and about 100 people will not appear.

\subsection{Test and Table Tennis's Basic Quality}

4.3.1. The Control Group Analyzes the Basic Quality of Table Tennis Every Time. For more accurate effectiveness gap between the use of the network multimedia table tennis teaching system for learning and traditional table tennis teaching methods, we analyzed the data of each test in the control group. Test the selected samples to obtain the mean, standard deviation, and standard error of the mean, as shown in Table 4.

It can be seen from Figure 6 that the score of the control group has increased in each basic quality test of table tennis, but the increase is not large. This may be because the control group has received not only traditional teaching methods for 


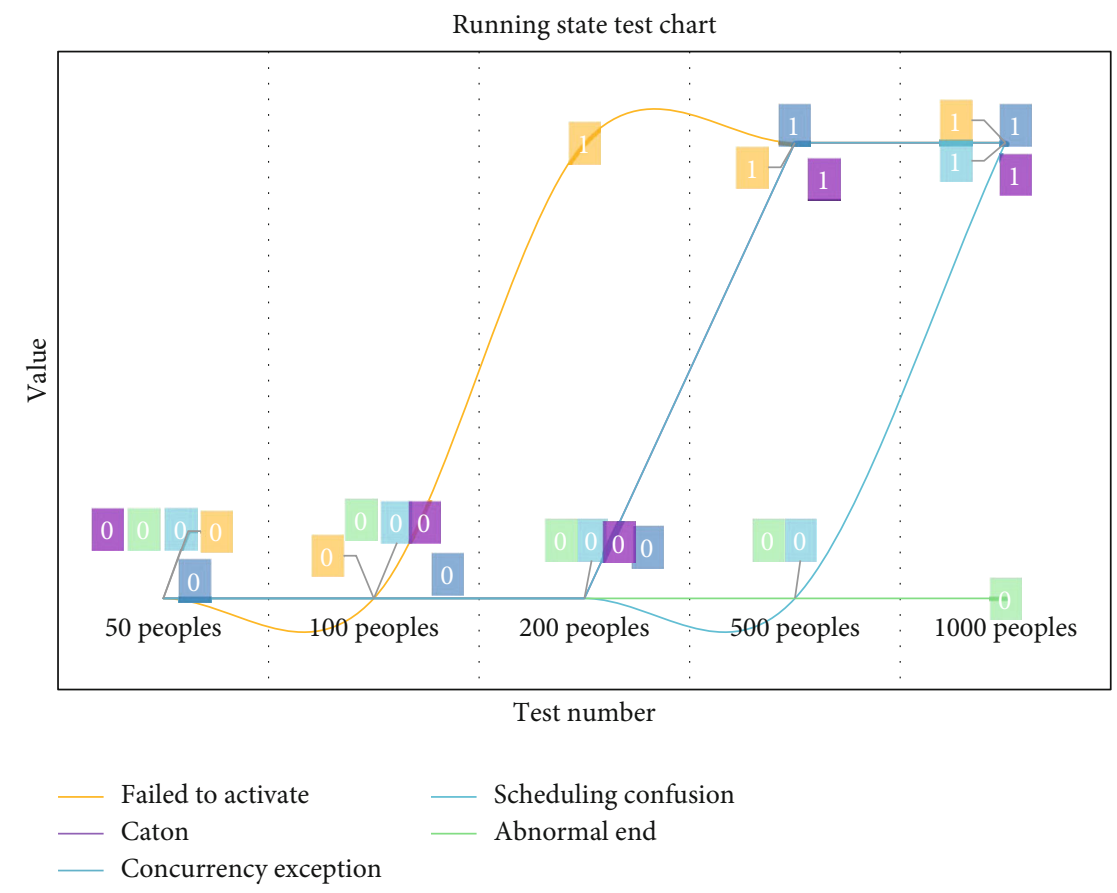

FIGURE 5: Running state test chart.

TABLE 4: Control group basic quality test data table.

\begin{tabular}{lcccc}
\hline & Mean & Standard deviation & Standard error of the mean & $P$ \\
\hline First test & 2.63 & 7.919 & 2.373 & 2.186 \\
Second test & 2.39 & 7.936 & 2.198 & 0.098 \\
Third test & 2.45 & 8.092 & 2.083 & 0.093 \\
Fourth test & 1.36 & 6.774 & 2.279 & 0.084 \\
Fifth test & 1.67 & 6.565 & 1.899 & 0.069 \\
Sixth test & 1.59 & 6.683 & & 0.071 \\
\hline
\end{tabular}

learning about table tennis but also daily practice table tennis training. At the same time, each test score of the control group was tested in pairs, and the error values were all greater than 0.05 , indicating traditional teaching methods. Actually, imagine.

4.3.2. The Experimental Group Analyzes the Basic Quality of Table Tennis Every Time. Effectiveness gap between using the network multimedia table tennis teaching system for learning and traditional table tennis teaching methods, we analyzed the data of each test of the experimental group. Test the selected samples to obtain the mean, standard deviation, and standard error of the mean, as shown in Table 5.

It can be seen from Figure 7 that the experimental group has a significant increase in the scores of each basic quality test of table tennis. This is to exclude the students' own learning factors, which is sufficient to prove that the use of our network multimedia table tennis teaching system is better than traditional teaching methods. It is easier for students to accept. They believe that multimedia online learning increases learning and the way of communication is a useful and necessary supplement to the learning and communication of table tennis courses.

\subsection{Questionnaire Analysis}

4.4.1. System Structure and Function. Here, we first analyze the students, the evaluation is divided into 5 levels (very satisfied, satisfied, general, unsatisfied, and very unsatisfied), we sorted out the data according to the students' evaluation, and the results are shown in Table 6 .

From $F>0.80$, it shows that students agree with the system function and the division of authority. Students think that the navigation of the website is clear and convenient, and it is easy for teachers and students to use. They think that the file download function is convenient for obtaining valuable information. Students think that news announcements and system announcements are convenient for them to learn about school table tennis information in time. For $F=0.39>0$, it indicates that the interface design and arrangement of the website system need to be further improved. The specific situation is shown in Figure 8 . 


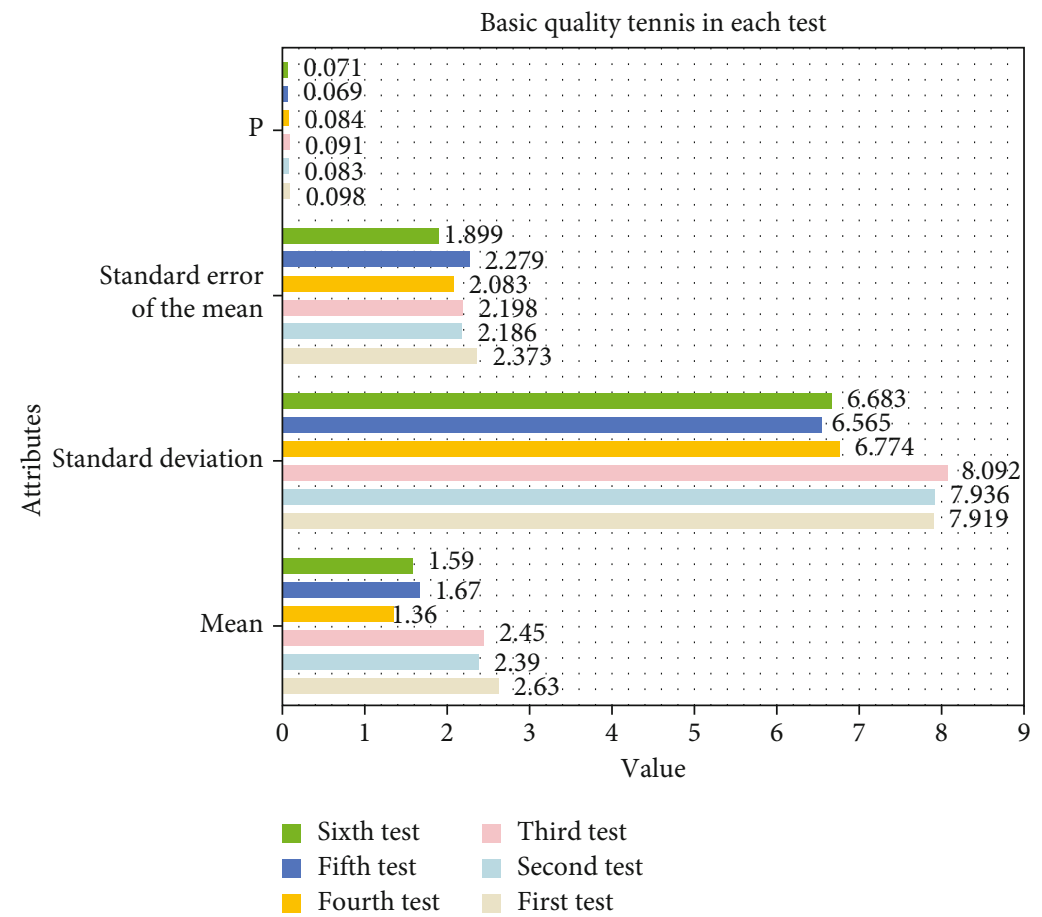

Figure 6: Basic quality of table tennis in each test of the control group.

TABLE 5: Experimental group basic quality test data sheet.

\begin{tabular}{lcccc}
\hline & Mean & Standard deviation & Standard error of the mean & $P$ \\
\hline First test & 2.96 & 10.027 & 3.016 & 3.158 \\
Second test & 2.84 & 9.982 & 3.176 & 0.005 \\
Third test & 2.71 & 9.756 & 3.569 & 0.004 \\
Fourth test & 3.54 & 8.357 & 3.677 & 0.002 \\
Fifth test & 3.60 & 8.588 & 3.546 & 0.001 \\
Sixth test & 3.99 & 8.776 & & 0.001 \\
\hline
\end{tabular}

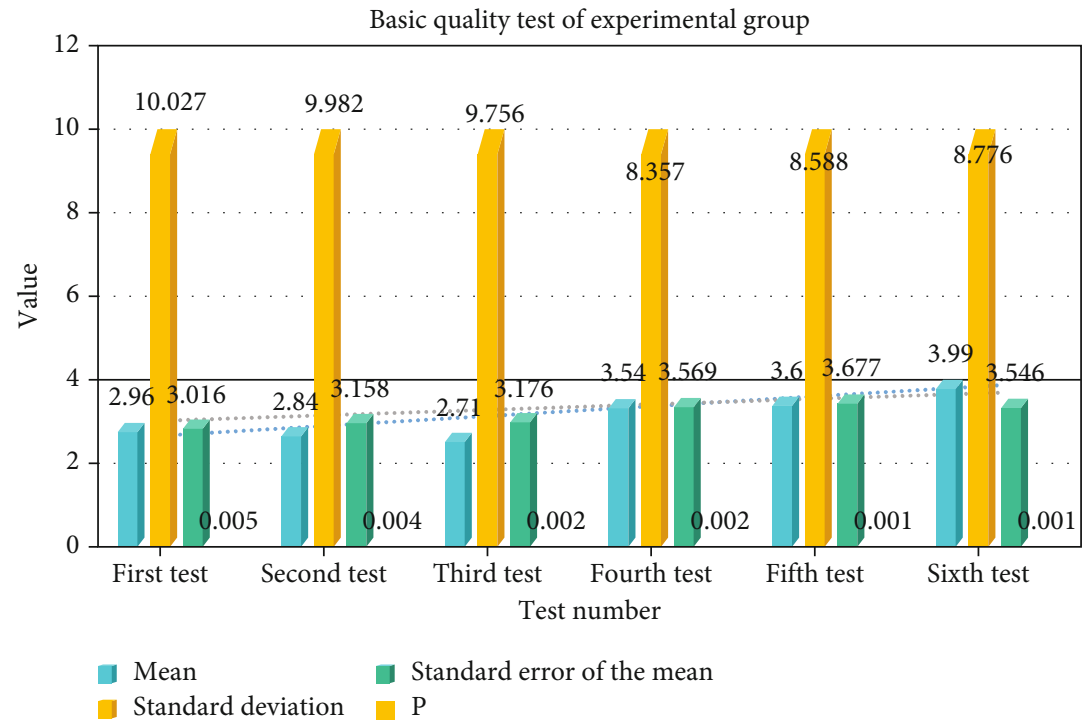

Figure 7: Basic quality test of the experimental group. 
TABLE 6: Survey data sheet for system structure and function.

\begin{tabular}{|c|c|c|c|c|c|c|}
\hline & Very satisfied & Satisfaction & General & Dissatisfied & Very dissatisfied & $F$ \\
\hline System functions & 6.31 & 6.43 & 6.84 & 6.58 & 6.66 & 0.89 \\
\hline Navigation function & 6.01 & 6.89 & 5.84 & 6.42 & 5.21 & 0.83 \\
\hline Download function & 7.94 & 7.19 & 5.89 & 6.65 & 5.56 & 0.92 \\
\hline Announcement function & 8.00 & 8.58 & 7.46 & 8.03 & 6.21 & 0.96 \\
\hline Interface design & 4.42 & 5.30 & 4.63 & 6.39 & 6.98 & 0.39 \\
\hline
\end{tabular}

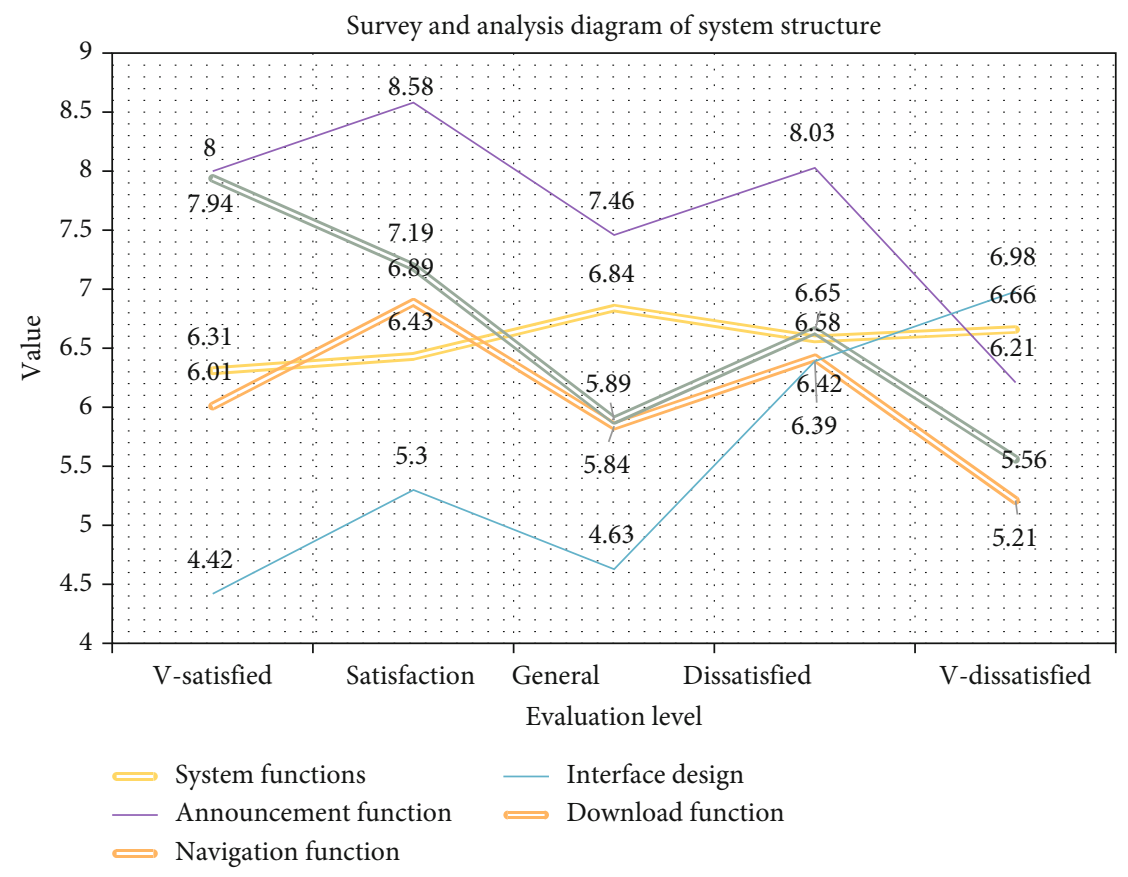

FIgURE 8: Survey and analysis diagram of system structure and function.

TABLe 7: Survey data sheet on learning effect and ability.

\begin{tabular}{|c|c|c|c|c|c|c|}
\hline & Very satisfied & Satisfaction & General & Dissatisfied & Very dissatisfied & $F$ \\
\hline Identification attitude & 3.78 & 5.16 & 4.74 & 5.73 & 6.26 & 0.87 \\
\hline Learning interest & 4.53 & 5.25 & 5.41 & 5.81 & 6.77 & 0.84 \\
\hline Learning ability & 4.61 & 5.77 & 5.52 & 6.13 & 8.00 & 0.92 \\
\hline Learning result & 4.78 & 6.10 & 5.77 & 7.81 & 8.09 & 0.91 \\
\hline Learning motivation & 6.12 & 5.83 & 7.16 & 6.75 & 8.75 & 0.90 \\
\hline
\end{tabular}




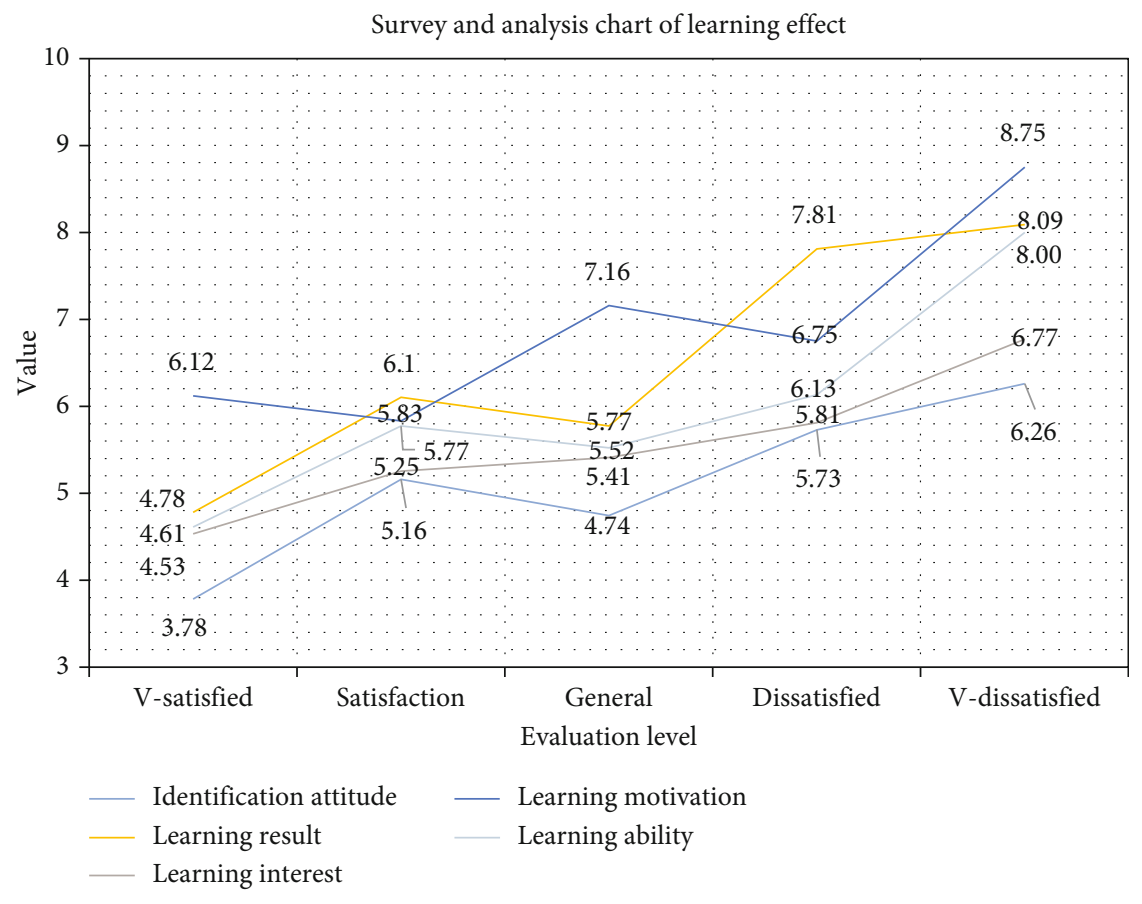

FIGURE 9: Survey and analysis chart of learning effect and ability.

4.4.2. Learning Effects and Abilities. We sorted it out according to the students' evaluation data. The results are shown in Table 7 .

It can be seen from Figure 9 that the multimedia table tennis teaching system is indeed effective in improving students' learning efficiency and improving students' understanding and memory of movements. And through the difference comparison of the batting stability of the two classes, it also shows this system students' mastery of technical movements.

\section{Conclusion}

Through the analysis of the student attitude questionnaire data, it can be seen that the students in the special table tennis class are very interested in the multimedia network learning method. They believe that the system platform has a reasonable functional structure, which is convenient for networked learning and communication, and can effectively improve the enthusiasm and motivation of learning. The learning effect is very helpful for cultivating independent learning ability. Most, and believe that multimedia network learning has increased the ways of learning and communication, and it is a useful and necessary supplement to the learning and communication of table tennis courses. The application of the platform increases the communication channels and access to knowledge, facilitates the management of teachers in teaching, improves the degree of informatization of course teaching, and is positive for the teaching reform of table tennis courses. The promotion function is a useful and necessary supplement to the teaching and communication of table tennis courses.
Services based on wireless networks have become increasingly extensive. Multimedia services have high requirements for network throughput and throughput stability, and wireless channels are susceptible to sudden interference from external noise and obstacles, causing a sudden drop in channel error rate, which puts forward a higher level for multimedia transmission congestion control protocols. Since the wired network does not have such a problem, the bit error rate of the channel can be ignored, and all packet losses can be considered as congested packet loss caused by link congestion. Therefore, the TFRC with outstanding performance in the wired network can no longer be used in wireless competence in the network. This paper studies the design and development of a network multimedia table tennis teaching system based on BS mode. Several common strategies for wireless network congestion control are analyzed. Among them, the end-to-end congestion control strategy has been extensively studied because the algorithm is simple to implement and conforms to the semantics of the traditional protocol, and innovation and innovation are made for the two processes of packet loss differentiation and rate control.

Through the results of the teaching experiment, we can see that the network multimedia teaching system can improve students' mastery of table tennis theoretical results and improve the test results of table tennis skills. Under the conventional teaching mode, the state of students learning whatever the teacher teaches is changed. At present, the market is mainly for single-core processors for industrial control or automotive electronics, but in multimedia mobile Internet devices, such as smart phone terminals, dual-core CPUs have occupied the main market, and quad-core CPUs have also been used to maturing in the product. In view of 
the work done in this article, the following directions for future work are proposed. At present, multicore processors have become the mainstream direction of the market. Therefore, research on multicore processors. In the research of cache and MMU, the cache and MMU units of highperformance processors are essential, especially in high-end chips, which affect the performance of processors. For the back-end design, because there is no tape-out, the actual performance of the chip cannot get accurate results. The embedded teaching experiment platform is a carrier that integrates embedded system design and many technologies, for the implementation of embedded system teaching experiments. Status quo of embedded technology and instructional design introduces the general flow of embedded product development. In the future, consider integrating the core board into the main board to achieve practical, concise, and beautiful effects.

\section{Data Availability}

All the data used is given in the paper.

\section{Conflicts of Interest}

The authors declare that they have no conflicts of interest.

\section{References}

[1] X. Ji, Q. Wang, B. W. Chen, S. Rho, C. C. J. Kuo, and Q. Dai, "Online distribution and interaction of video data in social multimedia network," Multimedia Tools and Applications, vol. 75, no. 20, pp. 12941-12954, 2016.

[2] S. W. Park, C. H. Cho, and S. B. Choi, "Social multimedia network service quality, user satisfaction, and prosumer activity," Multimedia Tools and Applications, vol. 76, no. 16, pp. 1721317229, 2017.

[3] M. Reza, R. Javidan, A. Fatemifar, and S. Einavipour, "Providing multimedia QoS methods over software defined networks: a comprehensive review," International Journal of Computer Applications, vol. 168, no. 9, pp. 55-59, 2017.

[4] J. H. Park, "Advances in algorithm, multimedia, and network for future IT," Journal of Information Processing Systems, vol. 13, no. 2, pp. 197-203, 2017.

[5] M. Li, "Smart home education and teaching effect of multimedia network teaching platform in piano music education," International Journal of Smart Home, vol. 10, no. 11, pp. 119-132, 2016.

[6] Y. Kang and S. Youm, "Multimedia application to an extended public transportation network in South Korea: optimal path search in a multimodal transit network," Multimedia Tools and Applications, vol. 76, no. 19, pp. 19945-19957, 2017.

[7] J. C. Granda, P. Nuño, J. Molleda, R. Usamentiaga, and D. F. García, "Resilient overlay network for real-time interactive multimedia sessions in corporate networks," Multimedia Systems, vol. 22, no. 5, pp. 543-557, 2016.

[8] X. Zhao, J. Jiang, and M. Stinnett, "Research on a structure of the multimedia list oriented network intrusion detection system," International Journal of Security and its Applications, vol. 10, no. 12, pp. 53-68, 2016.

[9] R. Borawake-Satao and R. Prasad, "Mobility aware multiobjective routing in wireless multimedia sensor network,"
Multimedia Tools and Applications, vol. 78, no. 23, pp. 32659-32677, 2019.

[10] Y. Li, Y. Zuo, H. Song, and Z. Lv, "Deep learning in security of internet of things," IEEE Internet of Things Journal, 2021.

[11] J. T. Wingate, R. Etzioni, D. M. Macdonald, and T. C. Brand, "Treatment trends for stage I testicular seminoma in an equal-access medical system," Clinical Genitourinary Cancer, vol. 14, no. 5, pp. 438-443, 2016.

[12] Y. Zhao, J. Xu, F. Xu, S. Song, and Y. Zhang, "Real-time localization in wireless sensor network with multimedia applications," Multimedia Tools and Applications, vol. 77, no. 16, pp. 21791-21801, 2018.

[13] N. Khernane, J. F. Couchot, and A. Mostefaoui, "Maximum network lifetime with optimal power/rate and routing tradeoff for wireless multimedia sensor networks," Computer Communications, vol. 124, no. JUN., pp. 1-16, 2018.

[14] Z. Zhang and K. K. R. Choo, "Guest editorial: multimedia social network security and applications," Multimedia Tools and Applications, vol. 76, no. 3, pp. 3163-3168, 2017.

[15] M. Lopez-Martin, B. Carro, J. Lloret, S. Egea, and A. SanchezEsguevillas, "Deep learning model for multimedia quality of experience prediction based on network flow packets," IEEE Communications Magazine, vol. 56, no. 9, pp. 110-117, 2018.

[16] P. Liu, J. Chai, and M. Zhu, "Analysis of the construction of individual table tennis teaching system based on cloud computing platform," Revista de la Facultad de Ingenieria, vol. 32, no. 12, pp. 781-787, 2017.

[17] S. Zhou, "Mechanical analysis of dynamic chain of table tennis in continuous movement," Boletin Tecnico/Technical Bulletin, vol. 55, no. 14, pp. 95-101, 2017.

[18] K. Yoshida, K. Yamada, S. Tamaki, and M. Kaga, "Perspectives on teaching and evaluating service movement in table tennis," Japanese Journal of Sport Education Studies, vol. 36, no. 2, pp. 49-59, 2016.

[19] L. Qu, "Design and fulfillment of table tennis training system using virtual simulation technology," Agro Food Industry HiTech, vol. 28, no. 1, pp. 3411-3414, 2017.

[20] O. Meriem and N. Bouyakoub, "Teaching and testing English in the Algerian educational system," Arab World English Journal, vol. 11, no. 1, pp. 444-458, 2020.

[21] E. J. Garba and D. T. Chinyio, "Computational model for creating neural network dataset of extracted features from images captured by multimedia security devices," ICTACT Journal on Image and Video Processing, vol. 9, no. 3, pp. 1947-1953, 2019.

[22] C. Sivaprakash and A. Pauline, "Configuring Linux system for internet protocol based multimedia communication network," Indian Journal of ence and Technology, vol. 10, no. 7, pp. 1-6, 2017.

[23] H. Wei and N. Kehtarnavaz, "Semi-supervised faster rcnnbased person detection and load classification for far field video surveillance," Machine Learning and Knowledge Extraction, vol. 1, no. 3, pp. 756-767, 2019.

[24] C. Lu, "Wireless multimedia network feasible path routing algorithm," Acta Technica CSAV (Ceskoslovensk Akademie Ved), vol. 62, no. 1, pp. 403-414, 2017. 